\title{
BMJ Open Educational inequalities in premature mortality in Poland, 2002-2011: a population-based cross-sectional study
}

\author{
Małgorzata Pikala, ${ }^{1}$ Monika Burzyńska, ${ }^{1}$ Robert Pikala, ${ }^{2}$ Marek Bryła, ${ }^{3}$ \\ Irena Maniecka-Bryła ${ }^{1}$
}

To cite: Pikala M, Burzyńska M, Pikala R, et al. Educational inequalities in premature mortality in Poland, 2002-2011: a population-based crosssectional study. BMJ Open 2016;6: 011501.

doi:10.1136/bmjopen-2016011501

- Prepublication history for this paper is available online. To view these files please visit the journal online (http://dx.doi.org/10.1136/ bmjopen-2016-011501).

Received 12 February 2016 Revised 21 August 2016 Accepted 26 August 2016

CrossMark

${ }^{1}$ Department of Epidemiology and Biostatistics, The Chair of Social and Preventive Medicine of the Medical University of Lodz, Lodz, Poland

${ }^{2}$ Faculty of Technical Physics, Information Technology and Applied Mathematics, Lodz University of Technology, Lodz, Poland

${ }^{3}$ Department of Social Medicine, The Chair of Social and Preventive Medicine of the Medical University of Lodz, Lodz, Poland

Correspondence to Dr Małgorzata Pikala; malgorzata.pikala@umed. lodz.pl

\section{ABSTRACT}

Background: The aim of the study is to evaluate the differences in premature mortality between educational groups of Polish inhabitants in 2002 and 2011.

Methods: The analysis included all deaths among inhabitants of Poland, aged 25-64 years, which occurred in 2002 ( $\mathrm{N}=97004)$ and 2011 ( $\mathrm{N}=104$ 598). We calculated age-standardised death rates (SDRs) and summary measures on inequalities. The relative index of inequality (RII) was calculated with Poisson regression.

Results: The SDR for Poland decreased from 285.7 per 100000 in 2002 to 246.0 in 2011 among males with higher education and increased from 1141.0 in 2002 to 1183.0 in 2011 among males with lower secondary or less education (the rate ratio increased from 4.0 to 4.8). With regard to females with higher education, the SDR decreased from 127.2 per 100000 in 2002 to 115.6 in 2011. Among females with lower secondary or less education, the SDR increased from 375.8 per 100000 in 2002 to 423.1 in 2011 (the rate ratio increased from 3.0 to 3.7 ). The RII increased from 5.8 to 9.7 in the male group and from 4.4 to 8.3 in the female group. The greatest educational inequalities in 2011 were observed in females who died of cardiovascular diseases (RII=14.9) and lung cancer (RII=6.6) and in males who died of suicides (RII=19.3) and lung cancer (RII=11.9).

Conclusions: Educational inequalities in premature mortality in Poland are growing. There is a need to implement health education programmes targeted at groups of the most poorly educated Polish inhabitants, especially for diseases resulting from smoking and excessive alcohol consumption.

\section{BACKGROUND}

According to the definition proposed by Whitehead, ${ }^{1}$ health inequalities refer to "differences in health which are not only unnecessary and avoidable but, in addition, are considered unfair and unjust". Reducing social and territorial differences in the health of the population is currently one of the most crucial problems faced by public health organisations all over the world.

\section{Strengths and limitations of this study}

- The data analysis included all deaths of Polish inhabitants aged 25-64 years which occurred in 2002 and in 2011, except those with no information concerning educational level.

- The methodology of the study allows the results obtained in Poland to be compared with those of other studies carried out in other European countries.

- Data on the numbers of Polish citizens with a particular type of education were obtained from censuses performed in Poland approximately every 10 years. Therefore, the study analyses the years 2002 and 2011 without the intervening period.

Many studies indicate that the level of education is the most important indicator of socioeconomic status. Other social parameters, such as profession and income, are greatly accounted for by differences in educational levels. University graduates are more likely to enjoy job stability, higher incomes, better work conditions and housing conditions. In addition, they are more aware of the benefits arising from a healthy lifestyle: they smoke less frequently, tend to eat a healthier diet and are more likely to engage in physical activities. ${ }^{23}$

The health differences associated with social status are widely discussed in the professional literature. A number of studies discuss the problem of differences in mortality rates in western European countries, ${ }^{4-11}$ while others have addressed health inequalities in eastern European countries, for example, Russia, ${ }^{12-14}$ Estonia $^{15}$ and Lithuania. ${ }^{16}$ These comparative analyses indicate that absolute differences are more noticeable in post-Soviet states than central European countries, ${ }^{17-19}$ and that greater differences exist between central and eastern 
European countries and western and Southern European countries. $^{20}$

The most recent study to examine inequalities in premature mortality analysed the changes occurring in the 1990s and the first decade of the 21st century in 13 European countries. ${ }^{21}$ The present article extends this analysis by examining the case of Poland between the years 2002 and 2011. Poland was the first member state of the eastern communist bloc to initiate constitutional, economic and social transformations in $1989,{ }^{22}$ aimed at fostering democracy and a free market, which contributed to an improvement in economic indicators. The gross domestic product (GDP) per capita increased from US $\$ 1698$ in 1990 to US\$14 422 in 2014. In the same period, the average annual GDP increase was $3.8 \% .^{23}$ The at-risk of poverty or social exclusion rates for Poland fell 18.1 percentage points from 2005 to 2011, when they were slightly higher than the average value for the European Union (EU): $27.2 \%$ of the population in Poland versus $24.3 \%$ for the 28 EU Member States (EU-28). Over the same period, the Gini coefficient in Poland fell 4.5 percentage points to $31.1 \%$ in 2011 , at which time it was only slightly higher than the mean rate in the EU-28 (30.8\%). ${ }^{24}$

The present paper evaluates the differences in allcause and cause-specific premature mortality between groups of Polish inhabitants according to education level and evaluates the changes in this field between the years 2002 and 2011.

\section{MATERIAL AND METHODS}

The analysis included all deaths with information on educational level among inhabitants of Poland, aged 2564 years, which occurred in $2002(\mathrm{~N}=97004)$ and 2011 $(\mathrm{N}=104598)$. Deaths below 25 years of age were excluded from the analysis because many people below that age were still in education. The analysis focused on premature mortality, that is, that occurring below 65 years of age, believed to be strongly influenced by social, economic and environmental factors and is a common indicator of health system performance. ${ }^{25}$ The study used unlinked cross-sectional design based on routinely collected data. The data on deaths by educational level were obtained from records of death certificates via the database of the Central Statistical Office in Poland, whereas data for population denominators for the same educational categories were retrieved from the censuses. Educational categories refer to the attained educational level. The Polish educational scheme has been reclassified into three categories corresponding to the International Standard Classification of Education (ISCED): lower secondary education or less (categories $0-2$ ), upper secondary education (categories 3-4) and higher education (categories 5-6). In addition to allcause mortality, the analysis included three main cause-of-death groups classified according to the 10th revision of the International Classification of Diseases
(ICD-10): cardiovascular diseases (I00-I99), malignant neoplasms (C00-C97), injuries (V01-Y98) and six causes characterised by the highest death rates within these groups: ischaemic heart disease (I20-I25), cerebrovascular disease (I60-I69), lung cancer (C33-C34), breast cancer (C50), road traffic accidents (V01-V99) and suicide (X60-X84).

Standardised death rates (SDRs) for total deaths and the main causes of death were calculated using the European Standard Population. To assess educational inequalities, rate ratio (RR), rate difference of lowest versus highest education group and population attributable risk (PAR) were used.

The PAR indicates proportional reduction in mortality rates that would occur in the hypothetical case that everyone experiences the rates of the highest socioeconomic group. The simplest way to calculate the PAR is to subtract the rate in the reference category from the rate in the total population, and then to divide it by the rate in the total population:

$$
\mathrm{PAR}=\left(\mathrm{SDR}_{\text {total }}-\mathrm{SDR}_{\mathrm{ref}}\right) / \mathrm{SDR}_{\text {total }} \times 100 \%
$$

The PAR reflects the mortality rates of lower secondary or less education groups as compared with higher education group, as well as their population size: larger groups with high rates were associated with greater potential reductions in overall rates.

In Poland, it generally takes 8 years to complete lower secondary education, 12 years to complete upper secondary education and 16 to complete higher education. Hence, education can be treated as a variable calculated with the use of an interval scale and more sophisticated, regression-based measures such as the relative index of inequality (RII) and the slope index of inequality (SII). RII can be interpreted as the ratio of mortality between a hypothetical person whose relative rank in the distribution of education is zero and a person whose relative rank in the cumulative distribution of education is $100 \%$. The RII was calculated with the use of Poisson regression analysis while the SII corresponds to the equivalent absolute rate difference between these two points. Further details on the RII and SII are available elsewhere. ${ }^{26}$

\section{RESULTS}

In 2002, the SDR in Poland was 778.6 per 100000 males aged 25-64 years, and its value varied according to level of education. The SDR was found to be 1141.0 in the male group with lower secondary or less education and 285.7 for the higher education group (table 1 ).

The RR, which reflects the ratio between SDRs in the group of males with lower secondary or less education and males with higher education, was 4.0 (95\% CI 3.5 to 4.5). In 2011, the SDR in males decreased to 680.3 per 100000 people, and simultaneously, inequalities by educational level increased. The SDR decreased by as much 
Table 1 Mortality by educational level, ages 25-64, 2002 and 2011, Poland

\begin{tabular}{|c|c|c|c|c|c|c|}
\hline Educational level & $\begin{array}{l}\text { Number of } \\
\text { persons }\end{array}$ & $\begin{array}{l}\text { Population } \\
\text { share (\%) }\end{array}$ & $\begin{array}{l}\text { Number of } \\
\text { deaths }\end{array}$ & $\begin{array}{l}\text { SDR (per } \\
100000)\end{array}$ & $\begin{array}{l}\text { Rate } \\
\text { ratio* }\end{array}$ & $\begin{array}{l}\text { Rate difference* } \\
\text { (per } 100000 \text { ) }\end{array}$ \\
\hline \multicolumn{7}{|l|}{2002} \\
\hline \multicolumn{7}{|l|}{ Men } \\
\hline Higher & 1401418 & 14.6 & 3346 & 285.7 & 1.0 & 0 \\
\hline Upper secondary & 6476302 & 67.4 & 40919 & 782.9 & 2.7 & 497.2 \\
\hline Lower secondary & 1735380 & 18.0 & 24358 & 1141.0 & 4.0 & 855.3 \\
\hline \multicolumn{7}{|l|}{ or less } \\
\hline Total & 9613100 & 100.0 & 68623 & 778.6 & NA & NA \\
\hline \multicolumn{7}{|l|}{ Women } \\
\hline Higher & 2146884 & 21.6 & 2037 & 127.2 & 1.0 & 0 \\
\hline Upper secondary & 5779433 & 58.2 & 14774 & 309.6 & 2.4 & 182.4 \\
\hline Lower secondary & 2010521 & 20.2 & 10654 & 375.8 & 3.0 & 248.6 \\
\hline \multicolumn{7}{|l|}{ or less } \\
\hline Total & 9936838 & 100.0 & 27465 & 284.2 & NA & NA \\
\hline \multicolumn{7}{|l|}{2011} \\
\hline \multicolumn{7}{|l|}{ Men } \\
\hline Higher & 2173829 & 21.0 & 4173 & 246.0 & 1.0 & 0 \\
\hline Upper secondary & 6930994 & 66.9 & 50238 & 688.4 & 2.8 & 442.4 \\
\hline Lower secondary & 1253365 & 12.1 & 18673 & 1183.0 & 4.8 & 937.0 \\
\hline \multicolumn{7}{|l|}{ or less } \\
\hline Total & 10358188 & 100.0 & 73084 & 680.3 & NA & NA \\
\hline \multicolumn{7}{|l|}{ Women } \\
\hline Higher & 3344703 & 31.7 & 2925 & 115.6 & 1.0 & 0 \\
\hline Upper secondary & 5951283 & 56.5 & 19086 & 272.3 & 2.4 & 156.7 \\
\hline Lower secondary & 1245420 & 11.8 & 7652 & 423.1 & 3.7 & 307.5 \\
\hline \multicolumn{7}{|l|}{ or less } \\
\hline Total & 10541406 & 100.0 & 29663 & 252.5 & NA & NA \\
\hline
\end{tabular}

${ }^{*}$ Versus higher educational level.

NA, not applicable; SDR, standardised death rate.

as 246.0 in the group of males with higher education, while the rate increased to 1183.0 per 100000 male population in the group of males with lower secondary or less education. As a consequence, the RR increased up to 4.8 (95\% CI 4.2 to 5.4). Similar tendencies were observed in the female group. The SDR decreased from 284.2 in 2002 to 252.5 in 2011 per 100000 female population. However, the decline was caused by a decreased value of the SDR in the group of females with higher education (127.2 vs 115.6, respectively) and in the group of females with upper secondary education (309.6 vs 272.3, respectively). With regard to females with lower secondary or less education, the SDR increased from 375.8 in 2002 to 423.1 in 2011 per 100000 female population, which led to an increase in the RR from 3.0 in 2002 (95\% CI 2.2 to $3.8)$ to 3.7 in 2011 (95\% CI 2.8 to 4.5$)$.

Over the period 2002-2011, the rate difference, which bears information on absolute differences in mortality between the least and most educated groups of people, increased from 855.3 (95\% CI 851.1 to 859.6) to 937.1 (95\% CI 932.2 to 941.9) per 100000 male population and from 248.6 (95\% CI 244.6 to 252.5$)$ to 307.5 (95\% CI 302.8 to 312.1 ) per 100000 female population.

The PAR implies that if mortality in all other educational groups were similar to that observed in the group of respondents with higher education, the overall mortality rate would have decreased by $63 \%$ in the male group and by $55 \%$ in the female group in 2002 (table 2).

Despite the statistically significant increase in the RR, the PAR for 2011 did not change because the proportion of persons with lower secondary or less education in the population decreased, while the proportion of higher educated people increased (table 1 ). With regard to absolute differences attributable to a decrease in overall mortality between 2002 and 2011, the absolute PAR value decreased from 492.9 to 434.4 per 100000 males and from 157.0 to 136.9 per 100000 females (table 2).

The RII demonstrates that the mortality ratio between the least and most educated males increased from 5.8 in 2002 to 9.7 in 2011 (table 2). The above value also grew from 4.4 to 8.3 in the female group. High RII values confirm that the level of education had a growing influence on mortality, as the impact of education is not balanced with an increase in the percentage of people who are most educated, as is the case in the PAR. According to the regression equation, the SII implies that the differences in mortality rates in the least and most educated people were 1058.5 in 2002 per 100000 males and 1095.2 in 2011 per 100000 males. In the female group, the SII value increased from 338.3 to 384.0 per 100000 females. 
Table 2 Summary measures on inequalities in premature mortality (and $95 \% \mathrm{Cl}$ ) according to level of education, ages 2564, 2002 and 2011, Poland

\begin{tabular}{|c|c|c|c|c|}
\hline \multirow[b]{2}{*}{ Summary measure } & \multicolumn{2}{|l|}{ Men } & \multicolumn{2}{|l|}{ Women } \\
\hline & 2002 & 2011 & 2002 & 2011 \\
\hline PAR (\%) & 63 (47 to 79$)$ & 64 (48 to 80 ) & 55 (31 to 80$)$ & 54 (32 to 76$)$ \\
\hline $\begin{array}{l}\text { PAR-absolute } \\
\text { version (per } \\
100000 \text { ) }\end{array}$ & 492.9 (488.5 to 497.4$)$ & 434.4 (430.2 to 438.6$)$ & 157.0 (152.8 to 161.1$)$ & $136.9(133.4$ to 140.4$)$ \\
\hline RII & 5.8 (4.9 to 6.7$)$ & 9.7 (8.8 to 10.6$)$ & 4.4 (3.9 to 4.9$)$ & 8.3 (7.7 to 8.9$)$ \\
\hline SII (per 100000$)$ & 1058.5 (973.7 to 1143.3 ) & 1095.2 (1014.8 to 1175.7$)$ & 338.3 (283.2 to 393.5 ) & 384.0 (330.9 to 437.2$)$ \\
\hline
\end{tabular}

An analysis of mortality by major causes of death highlights the huge changes which occurred between 2002 and 2011 in particular educational groups. For those with a lower secondary or less education, the SDR due to cardiovascular diseases (I00-I99) remained stable. For those with upper secondary and higher education, the SDR values dropped both in males and females (figure 1). As a consequence, the RII analysis indicated that differences resulting from the impact of educational levels on mortality rates due to cardiovascular diseases increased from 4.3 to 7.6 in the male group and from 8.8 to 14.9 in the female group (figure 2). The
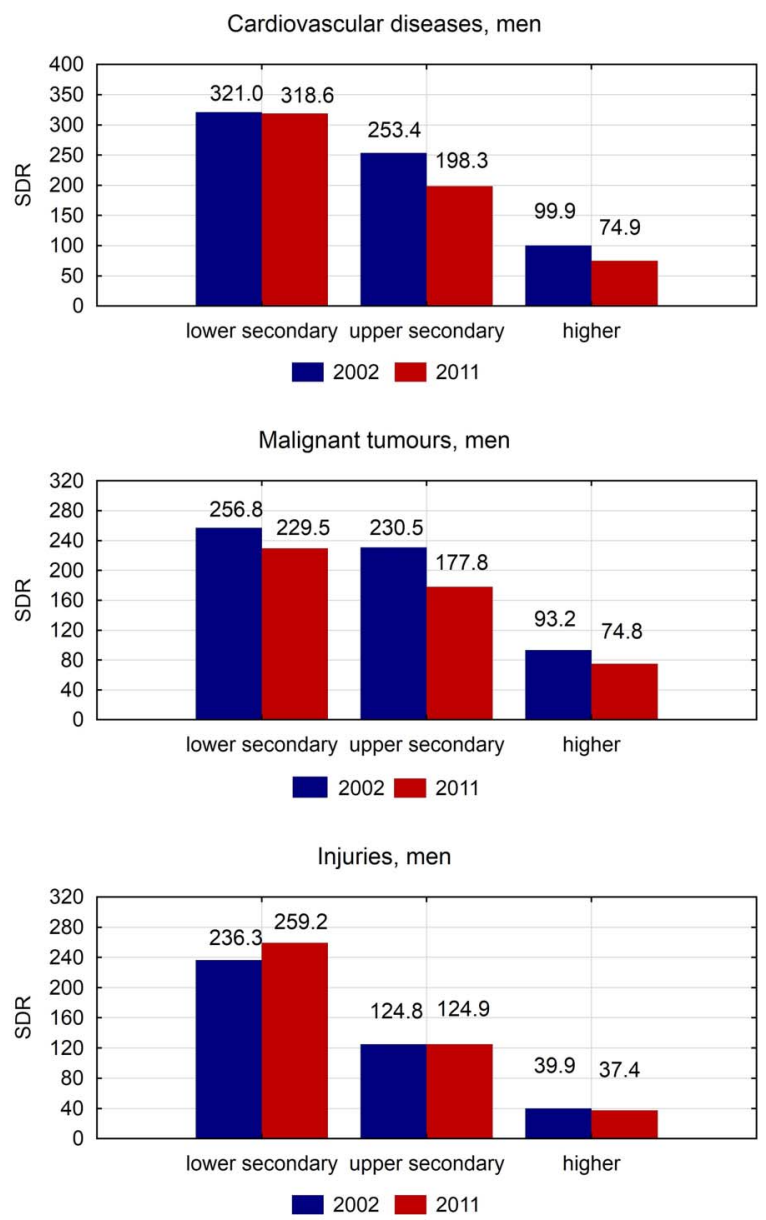

increasing influence of education also affected the SDR value with regard to two cardiovascular diseases-ischaemic heart disease (I20-I25) and cerebrovascular disease (I60-I69) being the most common causes of death.

With regard to malignant neoplasms (C00-C97), the SDR dropped between 2002 and 2011 for all cancers and groups (figure 1) except for lung cancer (C33C34) in females with less than higher education (figure 3). Whereas the absolute differences in lung cancer decreased for men, and increased for women (not significantly, table 3 ), the relative differences increased (figure 2). In 2002, the RII in the male group
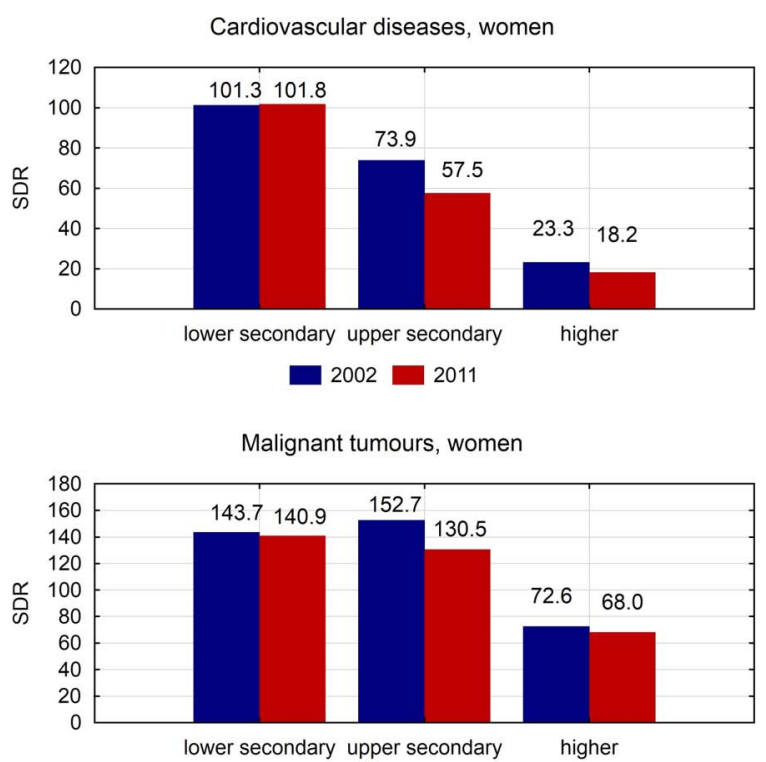

$\square 2002 \square 2011$

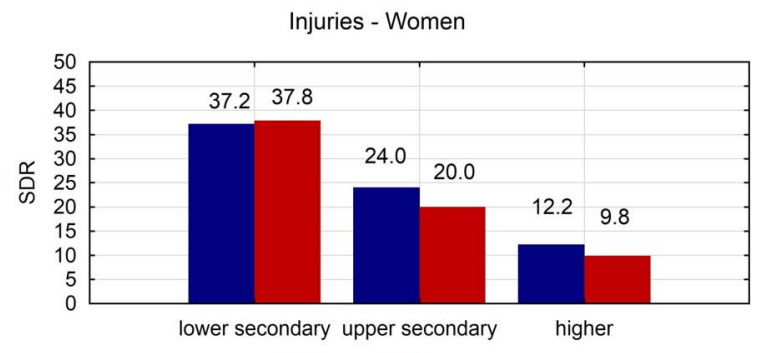

$2002 \square 2011$

Figure 1 Standardised death rates (SDRs) per 100000 population by main groups, sex and education level, ages 25-64, 2002 and 2011, Poland. 
A

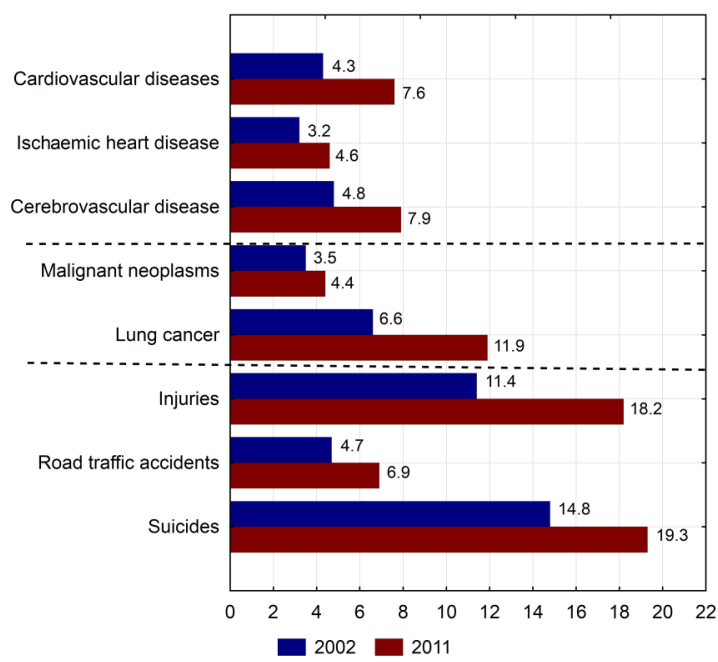

B

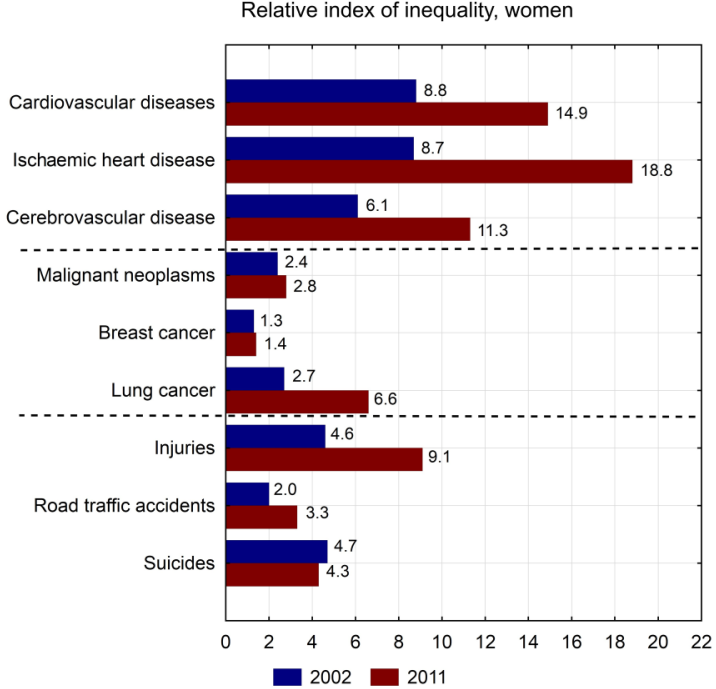

Figure 2 Relative index of inequality of premature mortality per 100000 population according to cause of death, ages 25-64, 2002 and 2011, Poland.

was 3.5 , rising to 4.4 in 2011 . With regard to females, the values in 2002 and 2011 were 2.4 and 2.8, respectively. The lowest value of the RII referred to the SDR due to breast cancer (C50) in the female group (1.3 in 2002 and 1.4 in 2011).

For the third most common cause of death in Poland, injuries (V01-Y98), a strong relationship was observed between death rates and level of education, as were negative changes between the years 2002 and 2011. The SDR values increased in females with lower secondary or less education and males with lower secondary or less and upper secondary education (figure 1 ). These negative changes were mostly caused by male suicides (X60-X84) (figure 3). The RII value due to this cause of death increased in the male group from 14.8 in 2002 to 19.3 in 2011 (figure 2). It is worthwhile noting the reducing inequalities in suicides among women. The value of SDRs decreased in all educational groups, but the decrease was greater in the group with lower secondary or less and upper secondary education; therefore, the SII and RII values decreased. The SII decline was reported also for traffic accidents in men. SII index values according to the causes of death are contained in table 3.

\section{DISCUSSION}

Inequalities in mortality rates according to educational level have increased in Poland. The mortality analyses confirmed that SDRs decreased between 2002 and 2011 in people with upper secondary and higher education, whereas they increased in people with lower secondary or less education. Our results indicate that educational differences in mortality increased in comparison to the last decade of the 20th century.

A previous study on educational inequalities in mortality conducted in four eastern European countries, Poland, Hungary, Estonia and Lithuania, from 1990 to
2000 demonstrates that different trends were observed between the two former Soviet republics and the two central-eastern European countries. In Estonia and Lithuania, mortality rates decreased among the highly educated, but increased among those who were poorly educated. In Poland and Hungary, mortality rates decreased or remained the same in all education groups. ${ }^{18}$

In the study where the authors analysed 3.2 million deaths in 13 European countries, relative inequalities in premature mortality increased in most populations in the northern, western and eastern regions of Europe. ${ }^{21}$ This was caused mainly by smaller proportional reductions in mortality among the lower educated than in the group with higher education. The results of the above study indicate that in Poland, as in the case of Lithuania and Estonia, mortality rose among the lower educated and declined among graduates in the period 2000-2010.

The study covering 13 European countries found mortality rates to be lowest in the group with higher education for most of the analysed causes of death. The greatest differences were observed for the occurrence of injuries, particularly suicides in the male group. Previous studies conducted on the number of years of life lost due to injuries confirm that suicides are becoming an increasingly serious problem in Poland. The problem particularly refers to less educated males, inhabitants of small towns and villages. ${ }^{27-29}$ Similar tendencies are observed in other eastern European countries, where socioeconomic changes and an increased unemployment rate have deprived many males of opportunities, resulting in feelings of social exclusion. ${ }^{30}$

The growing number of suicides probably has been associated with excessive alcohol consumption. ${ }^{31} \quad 32$ According to data published by the Central Statistical Office in Poland, the mean consumption of pure alcohol per person has gradually increased over the analysed 

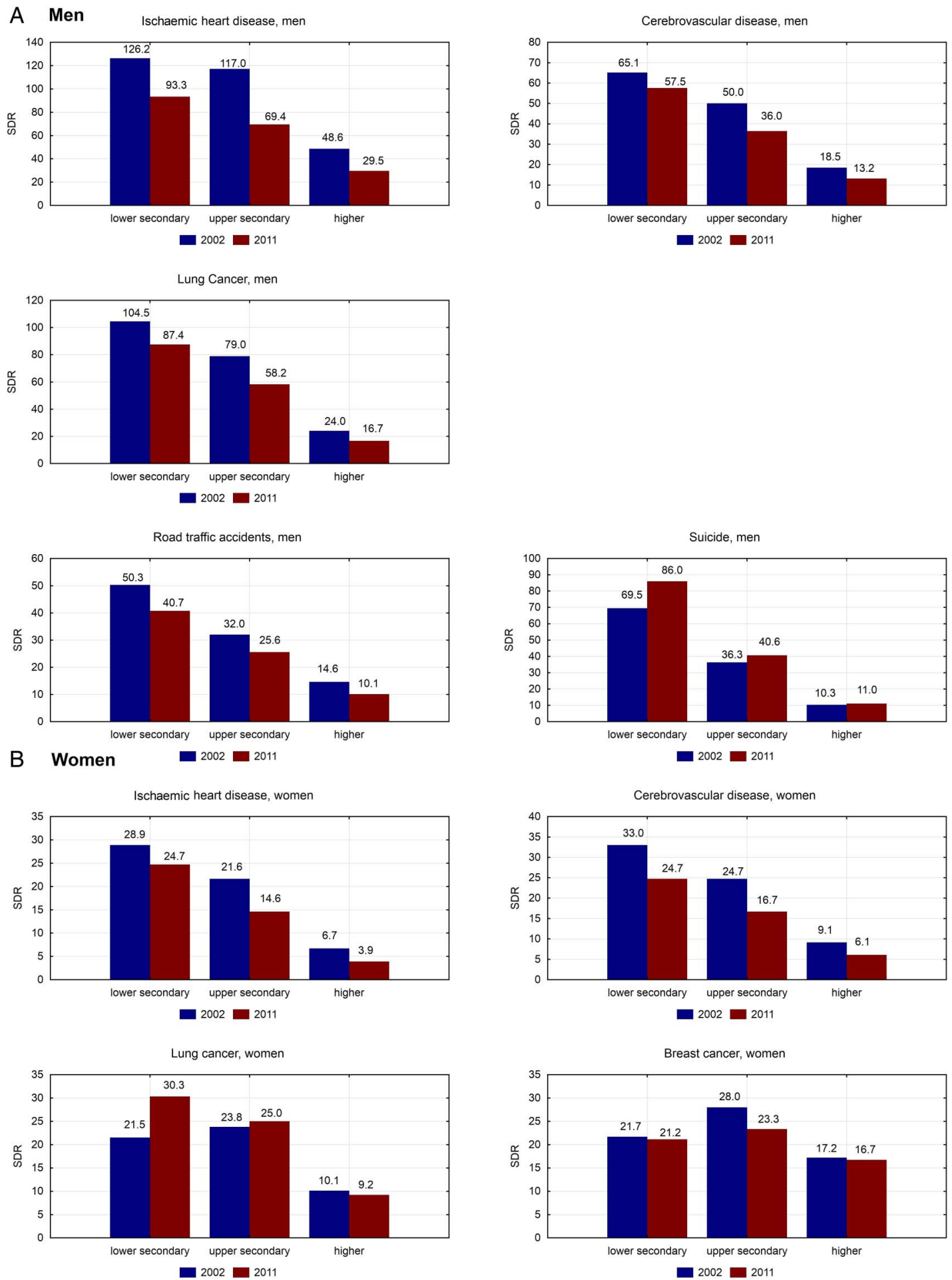

Road traffic accidents, women

Suicide, women
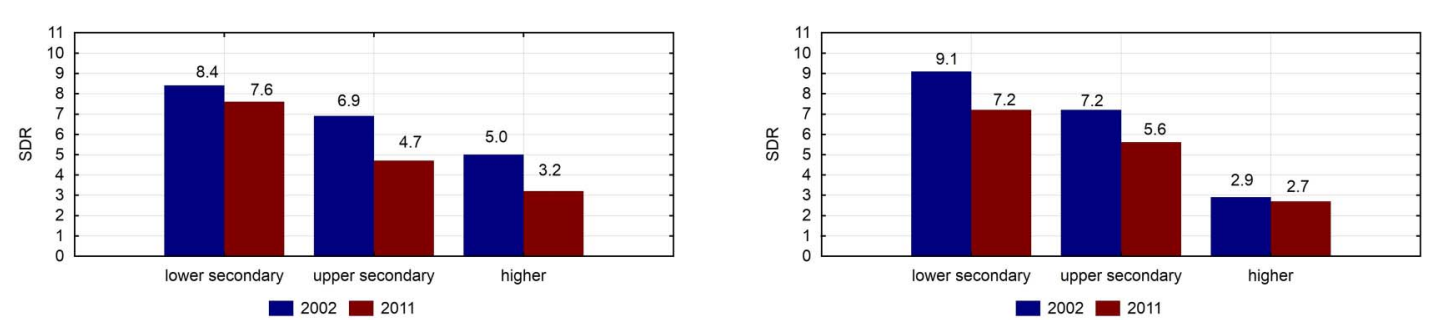

Figure 3 Standardised death rates (SDRs) per 100000 population by the most important disease entities and education level, ages 25-64, 2002 and 2011, Poland. 
Table 3 Slope index of inequality per 100000 persons (and 95\% Cl), ages 25-64, 2002 and 2011, Poland

\begin{tabular}{|c|c|c|c|c|}
\hline \multirow[b]{2}{*}{ Causes of death } & \multicolumn{2}{|l|}{ Men } & \multicolumn{2}{|l|}{ Women } \\
\hline & 2002 & 2011 & 2002 & 2011 \\
\hline Cardiovascular disease & 282.6 (235.1 to 330.2$)$ & 289.5 (246.5 to 332.4 ) & 104.7 (78.1 to 131.2$)$ & 102.0 (78.0 to 126.0$)$ \\
\hline Ischaemic heart disease & $103.1(71.4$ to 134.8$)$ & 79.2 (54.2 to 104.2$)$ & 30.1 (15.9 to 44.4$)$ & 25.9 (14.2 to 37.6$)$ \\
\hline Cerebrovascular disease & 59.4 (38.4 to 80.5$)$ & 52.9 (34.7 to 71.2$)$ & 31.8 (16.2 to 47.4$)$ & 23.8 (11.1 to 36.6$)$ \\
\hline Malignant neoplasms & 215.9 (171.4 to 260.5$)$ & 194.7 (155.0 to 234.5$)$ & 102.5 (64.4 to 140.6$)$ & $101.5(65.5$ to 137.5$)$ \\
\hline Lung cancer & 103.8 (78.0 to 129.6$)$ & 87.1 (65.0 to 109.3$)$ & 16.9 (2.2 to 31.6$)$ & $28.9(13.8$ to 44.1$)$ \\
\hline Breast cancer & - & - & 6.5 (10.0 to 23.1$)$ & 6.6 (9.2 to 22.4$)$ \\
\hline Injuries & 228.4 (193.3 to 263.5$)$ & 248.0 (213.1 to 283.0 ) & $31.2(14.7$ to 47.8$)$ & 32.7 (17.4 to 48.0$)$ \\
\hline Road traffic accidents & 42.6 (24.6 to 60.5$)$ & 36.4 (20.9 to 51.8$)$ & $4.4(2.6$ to 13.4$)$ & $5.2(2.5$ to 12.8$)$ \\
\hline Suicides & 69.0 (50.2 to 87.7$)$ & 83.6 (63.8 to 103.4$)$ & $8.3(0.2$ to 16.7$)$ & 6.0 (1.6 to 13.5$)$ \\
\hline
\end{tabular}

period, rising from 6.9 litres per person in 2002 to 9.3 litres in 2011. In addition, adverse changes in the structure of alcohol consumption are observed. Consumption of strong alcohol increased from $24.5 \%$ in 2002 to $35.7 \%$ in $2011 .{ }^{33}$ The Polish experience illustrates that the impact of rapid political and economic transitions on alcohol consumption and associated mortality is highly differentiated and specific to gender and social class. Patterns of mortality and their magnitude of change correspond to average alcohol consumption and are therefore different for men and women, for different age and educational groups and in urban and rural areas. Level of education, however, may affect alcohol-related mortality more strongly than overall alcohol intake, particularly with regard to acute consequences of drinking. ${ }^{34}$

Women are not affected by the above negative suicide trends to such an extent as men. They are protected by maternity duties, use social help more often than males and are less prone to risk-taking and becoming addicted to alcohol. ${ }^{35}$

Despite decreasing standardised mortality rates due to traffic accidents in all educational groups in both sexes, the mortality rates in Poland because of this group of causes still are among the highest in Europe. In 2011, higher SDR values occurred only in Romania. ${ }^{36}$ The high level of mortality due to traffic accidents in Poland, as in other Eastern European countries, is caused by the poor quality of road infrastructure, poor technical condition of vehicles and dangerous behaviour of road users, mostly among men, who, above all, exceed speed limits and drive under the influence of alcohol. ${ }^{37}$

It is worth stressing that since 1991, premature mortality due to cardiovascular diseases has been rapidly decreasing in Poland. ${ }^{38}{ }^{39}$ However, the results of the above study indicate that the decrease is not the same in all educational groups. In males with lower secondary or less education, the SDR value has slightly decreased and in females with lower secondary or less education the rate has increased. We should point out negative trends which occur in Poland compared with countries of northern, western and Southern Europe where a greater decrease in mortality due to cardiovascular diseases was observed in less educated than more educated people. ${ }^{21}$
With regard to malignant neoplasms, the most negative trends in premature mortality due to lung cancer were observed in females from the groups of people with upper secondary and lower secondary or less educational levels.

These findings are undoubtedly closely related to changes in smoking trends. Over several decades, the prevalence of smoking decreased substantially in Poland from $66 \%$ and $32 \%$ in 1982 to $33 \%$ and $21 \%$ in 2010 for men and women, respectively. ${ }^{40}$ Unfortunately, recent years have seen an end to the falling trend among the adult population. ${ }^{41}{ }^{42}$ Smoking prevalence is significantly higher among the lower educated part of the population compared with those with a university degree. ${ }^{40}$

The smallest educational differences were related to breast cancer mortality, as also noted by studies conducted in other countries. A survey covering 11 countries in Western and Northern Europe showed the reversed social gradient: higher breast cancer mortality being observed in the higher educated group. Women with a higher educational level had an $\sim 15 \%$ greater risk of dying from breast cancer than those with a lower level of education. ${ }^{43}$ In addition, a previous study covering the countries in the Baltic Sea region of Poland, Lithuania, Estonia, Finland and Sweden conducted in the early years of the 21st century reports the risk of death from breast cancer to be higher among bettereducated women. ${ }^{44}$ The results of this study show that mortality is slightly higher in the lower educated women, perhaps through fewer people attending screening programmes. ${ }^{45}$

Our findings indicate that the benefits of the economic growth of the 2000s contribute to improving the health condition of people with upper secondary and higher education, but not of people with lower secondary or less education. In the case of some diseases, improvements have occurred but to a lesser extent.

\section{Limitations}

Quality of the analyses performed on the mortality statistics depend on the completeness and accuracy of the information contained in the death certificate and the proper and precise description of the cause of death. 
Poland is a country with $100 \%$ completeness of death registration, but the quality of coding the cause of death is unsatisfactory. The data relating to 2012 shows that the causes of more than 28\% of deaths (about 109000 ) were inaccurately described. This high percentage of deaths recorded with 'garbage codes' is mainly a result of excessive use of inappropriate descriptions and indications related to cardiovascular disease, these being indicated as the cause of over $20 \%$ (78 500) of all deaths in Poland. ${ }^{46}$

A total of $0.9 \%$ of all death certificates issued in 2002 lacked data on education level and 1.8\% in 2011. Data on the number of people in each educational group, that is, the denominator of death rates, were obtained from the censuses in 2002 and 2011. The percentage of people with undetermined education was 2.0 in 2002 and 5.2 in 2011. ${ }^{47}$ In view of the significant increase in the temporary emigration rate, following Polish accession to the EU in 2004, the number and profile of the emigrants were developed in the census on the basis of generalised results of the sample survey. Both the death certificates with missing information about education, and those for people with undetermined education given in the census were excluded from the analysis.

Previous studies comparing national mortality rates with indirect estimates from the census suggest that under-registration is particularly important in the poorest regions, implying that estimates of disparities in mortality by educational level are likely to be an underestimation, because those with lower education are more likely to live in areas with higher under-registration rates. The results of this study therefore are indicative of potentially larger inequalities in mortality by education, which continue to increase. ${ }^{48}$

\section{CONCLUSIONS}

Inequalities in the education-dependent mortality rate in Poland have been increasing. The greatest differences arising from the level of education were observed in females who died of cardiovascular diseases and lung cancer and in males who died of suicides and lung cancer. The most effective way of reducing the inequalities observed between educational groups would be to decrease mortality due to smoking-related diseases and excessive consumption of alcohol in the group with the lowest levels of education.

Contributors All authors contributed to the writing of the manuscript. MP is the primary author and was involved in preparing the idea and methodology of the study: research questions and plan of analysis, and performing statistical analysis. MBu participated in preparing and editing the manuscript. $\mathrm{RP}$ developed the statistical procedure and performed the statistical analysis. $\mathrm{MBr}$ was responsible for selecting literature. IMB participated in preparing the methodology of the study.

Funding This work was supported by National Science Centre (grant number DEC-2013/11/B/HS4/00465).

Competing interests None declared.
Ethics approval Bioethics Committee of the Medical University of Lodz (number RNN/422/12/KB).

Provenance and peer review Not commissioned; externally peer reviewed.

Data sharing statement No additional data are available.

Open Access This is an Open Access article distributed in accordance with the Creative Commons Attribution Non Commercial (CC BY-NC 4.0) license, which permits others to distribute, remix, adapt, build upon this work noncommercially, and license their derivative works on different terms, provided the original work is properly cited and the use is non-commercial. See: http:// creativecommons.org/licenses/by-nc/4.0/

\section{REFERENCES}

1. Whitehead M. The concepts and principles of equity and health. Copenhagen: WHO/EURO, 1990.

2. Ross CE, Mirowsky J. Refining the association between education and health. The effects of quantity, credential and selectivity. Demography 1999;36:445-60.

3. Pikala M, Kaleta D, Bielecki W, et al. Awareness of cardiovascular prevention methods among residents of post-communist Polish provinces with highest mortality rates. Cent Eur J Public Health 2011;19:183-9.

4. Huisman M, Kunst AE, Andersen O, et al. Socioeconomic inequalities in mortality among elderly people in 11 European populations. J Epidemiol Community Health 2004;58:468-75.

5. Mackenbach JP, Bos V, Andersen O. Widening socioeconomic inequalities in mortality in six Western European countries. Int J Epidemiol 2003;32:830-7.

6. Kunst $A E$, Bos V, Lahelma $E$, et al. Trends in socioeconomic inequalities in self-assessed health in 10 European countries. Int J Epidemiol 2005;34:295-305.

7. Stronks $\mathrm{K}$, van de Mheen $\mathrm{H}$, van den Bos J, et al. The interrelationship between income, health and employment status. Int J Epidemiol 1997;26:592-600.

8. Lahelma E, Martikainen P, Laaksonen M, et al. Pathways between socioeconomic determinants of health. J Epidemiol Community Health 2004;58:327-32.

9. Deboosere P, Gadeyne S, Van Oyen H. The 1991-2004 evolution in life expectancy by education level in Belgium based on linked census and population register data. Eur J Popul 2009;25:175-96.

10. Strand $\mathrm{BH}$, Groholt EK, Steingrimsdottir OA, et al. Educational inequalities in mortality over four decades in Norway: prospective study of middle aged men and women followed for cause specific mortality, 1960-2000. BMJ 2010;340:c654.

11. Shkolnikov VM, Andreev EM, Jdanov DA, et al. Increasing absolute mortality disparities by education in Finland, Norway and Sweden, 1971-2000. J Epidemiol Community Health 2012;66:372-8.

12. Shkolnikov VM, Leon DA, Adamets S, et al. Educational level and adult mortality in Russia: an analysis of routine data 1979 to 1994. Soc Sci Med 1998;47:357-69.

13. Bobak M, Pikhart H, Hertzman C, et al. Socioeconomic factors, perceived control and self-reported health in Russia. A cross-sectional survey. Soc Sci Med 1998;47:269-79.

14. Murphy M, Bobak M, Nicholson A, et al. The widening gap in mortality by educational level in the Russian Federation, 1980-2001. Am J Public Health 2006;96:1293-9.

15. Leinsalu M, Vågerö D, Kunst AE. Estonia 1989-2000: enormous increase in mortality differences by education. Int $\mathrm{J}$ Epidemiol 2003;32:1081-7.

16. Shkolnikov VM, Jasilionis D, Andreev EM, et al. Linked versus unlinked estimates of mortality and length of life by education and marital status: evidence from the first record linkage study in Lithuania. Soc Sci Med 2007;64:1392-406.

17. Bobak M, Pikhart H, Rose R, et al. Socioeconomic factors, material inequalities, and perceived control in self-rated health: cross-sectional data from seven post-communist countries. Soc Sci Med 2000;51:1343-50.

18. Leinsalu $\mathrm{M}$, Stirbu I, Vågerö $\mathrm{D}$, et al. Educational inequalities in mortality in four Eastern European countries: divergence in trends during the post-communist transition from 1990 to 2000. Int J Epidemiol 2009;38:512-25.

19. Shkolnikov VM, Andreev EM, Jasilionis D, et al. The changing relation between education and life expectancy in central and Eastern Europe in the 1990s. J Epidemiol Community Health 2006;60:875-81.

20. Mackenbach JP, Stirbu I, Roskam AJR, et al. Socioeconomic inequalities in health in 22 European countries. $N$ Engl $\mathrm{J} \mathrm{Med}$ 2008;358:2468-81. 
21. Mackenbach JP, Kulhánová I, Menvielle G, et al. Trends in inequalities in premature mortality: a study of 3.2 million deaths in 13 European countries. J Epidemiol Community Health 2015;69:207-17.

22. Korbonski A. East Central Europe on the eve of the changeover: the case of Poland. Communist Post Communist Stud 1999;32: $139-53$.

23. World Bank. http://databank.worldbank.org/data/reports.aspx? source=world-development-indicators\# (accessed 20 Sep 2015)

24. European Union Statistics on Income and Living Conditions. http:// ec.europa.eu/eurostat/web/income-and-living-conditions/data/ database (accessed 15 Sep 2015).

25. Smith PC. Performance measurement for health system improvement: experiences, challenges and prospects. Cambridge University Press, 2010.

26. Mackenbach JP, Kunst AE. Measuring the magnitude of socioeconomic inequalities in health: an overview of available measures illustrated with two examples from Europe. Soc Sci Med 1997:44:757-71.

27. Pikala M, Bryła M, Bryła $P$, et al. Years of life lost due to external causes of death in the Lodz province, Poland. PLoS ONE 2014;9: e96830.

28. Maniecka-Bryła I, Bryła M, Bryła P, et al. The burden of premature mortality in Poland analysed with the use of standard expected years of life lost. BMC Public Health 2015;15:101.

29. Maniecka-Bryła I, Pikala M, Bryła M. Health inequalities among rura and urban inhabitants of Łódz Province, Poland. Ann Agric Environ Med 2012;19:723-31.

30. Möller-Leimkühler AM. The gender gap in suicide and premature death or: why are men so vulnerable? Eur Arch Psychiatry Clin Neurosci 2003;253:1-8.

31. Landberg J. Alcohol and suicide in Eastern Europe. Drug Alcohol Rev 2008;27:361-73.

32. Wålinder J, Rutzt W. Male depression and suicide. Int Clin Psychopharmacol 2001:16(Suppl 2):S21-24.

33. The state agency for the prevention of alcohol-related problems. http://www.parpa.pl/index.php/badania-i-informacje-statystyczne/ statystyki (accessed 11 Mar 2015).

34. Wojtyniak B, Moskalewicz J, Stokwiszewski J, et al. Gender-specific mortality associated with alcohol consumption in Poland in transition. Addiction 2005;100:1779-89.
35. Oquendo MA, Bongiovi-Garcia ME, Galfalvy $\mathrm{H}$, et al. Sex differences in clinical predictors of suicidal acts after major depression: a prospective study. Am J Psychiatry 2007;164:134-41.

36. Eurostat statistics. http://epp.eurostat.ec.europa.eu/portal/page/ portal/statistics/search_database (accessed 18 May 2015).

37. Skog OJ. Alcohol consumption and mortality rates from traffic accidents, accidental falls and other accidents in 14 European countries. Addiction 2001;96(Suppl 1):S49-58.

38. Bandosz P, O'Flaherty M, Drygas W, et al. Decline in mortality from coronary heart disease in Poland after socioeconomic transformation: modelling study. BMJ 2012;344:d8136.

39. Maniecka-Bryła I, Pikala M, Bryła M. Life years lost due to cardiovascular diseases. Kardiol Pol 2013;71:1065-72.

40. Kaleta D, Makowiec-Dabrowska T, Dziankowska-Zaborszczyk E, et al. Determinants of heavy smoking: results from the global adult tobacco survey in Poland (2009-2010). Int J Occup Med Environ Health 2012;25:66-79.

41. World Health Organization. The current status of the tobacco epidemic in Poland. Copenhagen: WHO, 2009.

42. Pikala M, Maniecka-Bryła I. Years of life lost due to malignant neoplasms characterized by the highest mortality rate. Arch Med Sci 2014; 10:999-1006

43. Strand BH, Kunst A, Huisman M, et al., EU Working Group on Socioeconomic Inequalities in Health. The reversed social gradient: higher breast cancer mortality in the higher educated compared to lower educated. A comparison of 11 European populations during the 1990s. Eur J Cancer 2007;43:1200-7.

44. Ezendam NP, Stirbu I, Leinsalu M, et al. Educational inequalities in cancer mortality differ greatly between countries around the Baltic Sea. Eur J Cancer 2008;44:454-64.

45. Dyzmann-Sroka A, Trojanowski M. Why Polish women do not attend preventive examinations? Med News 2012;81:258-64.

46. http://stat.gov.pl/download/gfx/portalinformacyjny/pl/defaultaktualnosci/ 5746/1/1/2/_na_co_umarl_pacjent.pdf

47. http://stat.gov.pl/download/gfx/portalinformacyjny/pl/defaultaktualnosci/ 5670/11/1/2/l ludnosc i gospodarstwa domowe nsp2011-1.pdf

48. de Vries E, Arroyave I, Pardo C. Time trends in educationa inequalities in cancer mortality in Colombia, 1998-2012. BMJ Open 2016;6:e008985. 